\title{
TRANSMISI MEMORI DAN WACANA REKONSILIASI DALAM CERPEN "PEREMPUAN SINTING DI DAPUR" KARYA UGORAN PRASAD: KAJIAN POSTMEMORY
}

Memory Transmission and Reconciliation Discourse in Ugoran Prasad's

"Perempuan Sinting di Dapur": A Study of Postmemory

\section{Galih Pangestu Jati}

Fakultas Ilmu Budaya, Universitas Gadjah Mada

Pos-el: gpangestujati@gmail.com

\begin{abstract}
Abstrak
Penelitian ini bertujuan untuk menjelaskan struktur transmisi memori dalam cerpen "Perempuan Sinting di Dapur" karya Ugoran Prasad dan wacana rekonsiliasi yang ditawarkan oleh penulis. Secara keseluruhan, cerpen ini mengangkat Peristiwa 1965 di Indonesia. Ugoran Prasad berusaha membahas mengenai dampak yang ditimbulkan dari peristiwa itu, baik dari segi pelaku maupun korban. Adapun teori yang digunakan adalah teori postmemory yang dikembangkan oleh Marianne Hirsch. Hasil dari penelitian ini menunjukkan bahwa struktur transmisi memori dalam cerpen dimediasi oleh perilaku dan narasi atau cerita, baik dari perspektif korban maupun pelaku. Kedua pihak ini ternyata sama-sama menyimpan trauma mendalam yang dibawa seumur hidupnya. Kemudian, melalui cerpen ini Ugoran Prasad menghadirkan wacana rekonsiliasi kepada pihak-pihak yang berdampak trauma akan Peristiwa 1965, baik generasi yang mengalami trauma maupun post-generation.
\end{abstract}

Kata-kata kunci: transmisi memori, postmemory, rekonsiliasi

\begin{abstract}
This study aims to explain the structure of memory transmission in the short story "Perempuan Sinting di Dapur" by Ugoran Prasad and the reconciliation discourse offered by the author. Overall, this short story raised the 1965 Event in Indonesia. Ugoran Prasad tried to discuss the impact caused by the incident, both in terms of the perpetrators and victims. The theory used is the postmemory theory developed by Marianne Hirsch. The results of this study indicate that the structure of memory transmission in short stories is mediated by behavior and narratives, both from the perspective of victims and perpetrators. Both of these parties turned out to be equally save the deep trauma that was carried throughout his life. Then, through this short story, Ugoran Prasad presented a discourse of reconciliation to those who had a traumatic impact on the 1965 event, both generations who were traumatized and post-generation.
\end{abstract}

Keywords: memory transmission, postmemory, reconciliation

How to Cite: Galih Pangestu Jati. (2020). Transmisi Memori dan Wacana Rekonsiliasi Dalam Cerpen "Perempuan Sinting di Dapur" Karya Ugoran Prasad: Kajian Postmemory. Jentera: Jurnal Kajian Sastra, 9(1), 28 42. doi: $10.26499 /$ jentera.v9i1.2265 


\section{PENDAHULUAN}

Hirsch mengatakan bahwa waktu memang bisa menyembuhkan segalanya, kecuali luka. Dengan berlalunya waktu, luka perpisahan kehilangan batas sebenarnya. Dengan waktu, tubuh yang diinginkan akan segera menghilang. Jika tubuh yang diinginkan sudah tidak ada lagi untuk yang lain, yang tersisa adalah luka. Hal semacam itulah yang dirasakan oleh Saodah dalam cerpen "Perempuan Sinting di Dapur". Meskipun telah puluhan tahun ia kehilangan suaminya, luka yang dialaminya tidak lantas sembuh. Luka itu masih menganga (Hirsch, 2012: 174).

Dalam cerpen tersebut diceritakan seorang tokoh bernama Wak Haji Mail yang memiliki tiga istri dan banyak anak. Saat itu ia sedang mengalami sekarat dan ingin bertemu dengan seorang perempuan yang hidup di kampungnya, yakni Saodah. Sebelum maut menjemput nyawanya, ia ingin sekali meminta maaf kepada Saodah atas kesalahan yang dilakukannya puluhan tahun yang lalu. Dahulu, Wak Haji Mail menjadi salah satu penyebab suami Saodah mati. Ia ikut menuding suami Saodah murtad, syirik, musyrik, dan kafir. Akibatnya, suami Saodah diasingkan orang sekampung seperti penderita kusta, lalu dibiarkan mati tanpa harga diri.

Secara keseluruhan, cerpen tersebut mengangkat Peristiwa 1965 di Indonesia. Ugoran Prasad berusaha mengangkat peristiwa tersebut dari sisi korban yang kehilangan orang tercintanya akibat peristiwa tersebut. Namun, bukan peristiwa ini yang menjadi fokus pembahasan, melainkan dampak dari peristiwa tersebut. Saodah merupakan korban yang membawa trauma atas peristiwa tersebut. Selain Saodah, Wak Haji Mail merupakan pihak yang memiliki trauma tersebut meskipun saat itu ia merupakan seorang pelaku atau perpetrator. Gejala-gejala psikologis dialami oleh Wak Haji Mail, seperti rasa bersalah. Namun, hal itu tetap membuat Saodah bergeming. Meskipun Wak Haji Mail telah berusaha untuk memperbaiki kesalahannya dahulu dengan ikut membantu kehidupan Saodah, ternyata hal itu tidak lantas membuat dirinya dimaafkan oleh Saodah. Luka yang dimiliki Saodah masih tetap ada, bahkan ia enggan memaafkan Wak Haji Mail. Trauma yang dimiliki oleh Saodah dan Wak Haji Mail ini pun dibawa selama hidupnya, bahkan ditransmisikan kepada generasi-generasi berikutnya.

Ada beberapa penelitian mengenai transmisi memori antargenerasi terkait dengan memori Peristiwa 1965. Namun, dalam penelitian tersebut hanya dibahas transmisi memori dalam lingkup korban (Assa, 2019; Jati, 2020; Putra, 2018). Padahal, pelaku atau perpetrator juga mengalami trauma yang diwariskan kepada generasi selanjutnya. Oleh 
karena itu, dalam tulisan ini akan dibahas transmisi memori yang dilakukan oleh generasi pertama kepada generasi setelahnya, baik oleh korban maupun pelaku. Selain itu, dalam penelitian ini akan dibahas wacana rekonsiliasi yang ditawarkan oleh Ugoran Prasad sebagai seorang seniman postmemory. Hal ini tidak bisa lepas dari fungsi karya sastra yang dapat menjadi penyimpanan memori kultural akan suatu peristiwa masa lalu (Saputro, 2013), khususnya dalam sudut pandang post-generation.

\section{LANDASAN TEORI}

Teori yang akan digunakan di dalam penelitian ini adalah teori yang disebut oleh Marianne Hirsch sebagai postmemory. Pada awalnya Hirsch melihat postmemory sebagai sebuah fenomena yang terkait dengan individu-individu yang tumbuh sebagai anak-anak yang selamat dari Holocaust. Ia menggunakan analisis terhadap novel grafis berjudul Maus karya Art Spiegelman sebagai titik awal untuk memikirkan bagaimana anak-anak korban Holocaust tumbuh dengan beban yang dibawa orang tua mereka dan sejauh mana cerita orang tua terjalin dalam ingatan anak-anak itu sendiri. Sejak artikel tersebut muncul, Hirsch terus mengembangkan gagasannya mengenai postmemory (Hirsch, 1992).

Seniman dan penulis generasi kedua memproduksi berbagai macam karya seni, film, novel, dan memoar mengenai Holocaust (Hirsch, 2012: 3). Uniknya, dalam karya-karya tersebut para seniman dan penulis merupakan keturunan dari penyintas (survivor) yang masih terhubung secara kuat dengan memori dari generasi sebelumnya. Generasi itulah yang disebut oleh Hirsch — meminjam istilah Eva Hoffman—sebagai post-generation. Dari situlah ia melihat bahwa memori bisa ditransfer kepada mereka yang tidak mengalami peristiwa traumatis tersebut. Kemudian, ia pun menawarkan konsep postmemory.

Postmemory membahas struktur transmisi memori antargenerasi (Hirsch, 2012: 5). Teori tersebut menggambarkan hubungan yang dialami oleh suatu generasi mengenai trauma personal, kolektif, dan kultural dari generasi yang sudah ada sebelumnya - terhadap pengalaman yang mereka ingat hanya dari cerita, imaji, dan perilaku di sekitar tempat mereka bertumbuh (Hirsch, 2012: 5). Koneksi postmemory terhadap masa lalu tidak dimediasi melalui recall, tetapi melalui investasi imajinatif, proyeksi, dan penciptaan. Recall merupakan proses "memanggil" kembali memori melalui storage sehingga memori tersebut dimiliki. Hal itu berbeda dengan postmemory. Dalam postmemory ia tidak memiliki memori, tetapi mendapat transmisi dari narasi. Dengan demikian, post-generation "merelakan" memorinya untuk didominasi oleh narasi nenek moyangnya atau generasi 
sebelumnya. Memori ini ditransmisikan secara mendalam dan efektif sehingga seolah-olah dimiliki oleh generasi penerima transmisi memori. Ini harus dibentuk, bagaimana pun secara tidak langsung, melalui fragmen traumatis dari peristiwa yang masih menentang rekonstruksi naratif dan melampaui pemahaman. Peristiwa tersebut terjadi pada masa lalu, tetapi efeknya terus berlanjut hingga saat ini.

Pada dasarnya, postmemory lebih menekankan pada sisi afektifnya. Gagasan tentang kekuatan afektif ini mengacu pada kapasitas tubuh untuk berubah dan diubah oleh dunia di sekitarnya (Anderson, 2006). Efek tersebut akan menyebabkan individu memiliki ikatan kuat secara emosional serta menentukan cara seorang individu memahami dan berinteraksi dengan dunia di sekitar mereka (Jones \& Osborne, 2020). Transmisi memori tidak menekankan diri terhadap identitas, tetapi lebih menekankan pada struktur generasional transmisi yang terjadi melalui berbagai macam bentuk mediasi (Hirsch, 2012: 35). Lebih lanjut, Hirsch membagi transmisi memori menjadi dua macam, yakni transmisi familial (familial transmision) dan transmisi afiliatif (affiliatve transmission). Yang pertama merupakan transmisi memori yang dilakukan dalam lingkup keluarga. Memori generasi sebelumnya mengenai peristiwa traumatis ditransmisikan kepada generasi postmemory melalui cerita-cerita dan fotografi. Sementara itu, affiliative transmision tidak lebih dari perpanjangan dari struktur keluarga yang dilonggarkan. Maksudnya, transmisi terjadi dalam lingkup yang lebih luas, di luar struktur keluarga. Transmisi tersebut dilakukan dengan seperangkat struktur mediasi yang menampung memori kolektif, seperti arsip budaya dan museum (Hirsch, 2012: 36). Dengan melihat dua jenis transmisi tersebut, kita juga dapat melihat bahwa Hirsch menekankan transmisi familial dan menjadikan transmisi afiliatif sebagai pelengkapnya.

Ada beberapa mediator yang berperan penting dalam transmisi memori ini, baik memori familial maupun memori afiliatif. Hirsch berpendapat bahwa "adopsi" publik, gambar-gambar anonim ke dalam album foto keluarga menemukan pasangannya dalam penggunaan pribadi, foto-foto dan benda-benda keluarga di berbagai institusi tampilan publik-museum dan peringatan seperti the Tower of Faces di Holocaust di Amerika Serikat atau pameran di Museum of Jewish Heritage di New York-yang dengan demikian membangun setiap pengunjung sebagai subjek keluarga. Dari pernyataan tersebut dapat dilihat bahwa mediator yang menjadi bagian dari transmisi memori, antara lain, ialah benda-benda keluarga, foto, dan arsip publik yang mencakup monumen dan museum. Bagi Hirsch, fotografi merupakan suatu hal yang cukup penting dalam mediasi postmemory. 
Menurutnya, peran kunci yang dimainkan gambar fotografi sebagai media postmemory memperjelas hubungan antara postmemory familial dan afiliatif. Selain itu, mekanisme arsip dan institusi publik telah mampu mewujudkan dan memilah kembali struktur ingatan budaya secara lebih jauh (Hirsch, 2012: 36).

Setelah memori ditransmisikan, post-generation akan melakukan rekonstruksi. Dalam tahapan rekonstruksi dapat dilihat bagaimana penerimaan yang dilakukan oleh postgeneration terhadap memori yang ditransmisikan. Dalam proses itu biasanya akan terjadi proses "koreksi" atau perubahan dari bentuk narasi aslinya. Post-generation bisa melakukan return journey, yakni melakukan perjalanan kembali ke tempat-tempat trauma. Objek kesaksian seperti itu, yang hilang dan ditemukan lagi, menyusun plot of return. Mereka dapat mewujudkan memori sehingga memicu pengaruh yang dibagikan secara lintas generasi. Mereka juga dapat memediasi klaim politik, ekonomi, dan yuridis perampasan dan pemulihan yang sering memotivasi kisah pengembalian (Hirsch, 2012: 206). Hal itu pun menyebabkan post-generation mengalami koneksi yang mengaktifkan ingatan dan dengan demikian mengaktifkan kembali trauma kehilangan. Dalam daftar mich-Gedachtnis atau "repertoar" yang lebih pasif, mereka mungkin tidak merilis data penuh dari masa lalu, tetapi mereka dapat mengembalikan masa lalu tersebut beserta efeknya (Hirsch, 2012: 212). Dalam melakukan returning journey, post-generation dapat juga melakukan riset terkait dengan arsip historis. Memori yang ditransmisikan oleh para penyintas akan berbeda, bergantung pada penerimaan para post-generation dan storage yang dimilikinya.

Proses selanjutnya adalah identifikasi. Identifikasi tersebut sangat penting karena berhubungan dengan pembentukan trauma terhadap post-generation. Hirsch membagi proses identifikasi menjadi dua cara, yakni heterophatic dan idiophatic. Heterophatic merupakan identifikasi yang dilakukan dengan cara menarik diri (self) keluar dari diri dan berempati terhadap yang lain (others). Dengan demikian, dalam identifikasi jenis ini, diri (self) merasakan simpati tanpa menjadikan diri bagian dari yang lain (others) sehingga di sini tercipta jarak antara diri (self) dan yang lain (others). Sebaliknya, idiophatic merupakan identifikasi yang menjadikan diri sebagai bagian yang lain (others) kepada diri (self). Tidak ada batas antara diri (self) dengan yang lain (others) (Hirsch, 2012: 85-86). Identifikasi ini cenderung negatif karena post-generation benar-benar tidak bisa membedakan dirinya dengan generasi sebelumnya. Postmemory cenderung terhadap 
identifikasi heterophatic karena post-generation memiliki jarak di antara diri (self) dan yang lain (others).

\section{METODE PENELITIAN}

Metode penelitian adalah cara untuk memperoleh pengetahuan mengenai objek tertentu sehingga harus sesuai dengan kodrat keberadaan objek itu sebagaimana yang dinyatakan oleh teori (Faruk, 2012: 55). Dalam penelitian ini dilakukan dua tahapan penelitian, yakni pengumpulan data dan analisis data. Adapun data yang dimaksud dalam penelitian ini adalah satuan tekstual yang berhubungan dengan teori postmemory yang dikembangkan oleh Marianne Hirsch. Data dapat dibedakan menjadi dua, yakni data primer dan data sekunder. Data primer terdiri atas beberapa paragraf yang diperoleh dari cerpen "Perempuan Sinting di Dapur" yang berhubungan dengan konsep postmemory. Kemudian, data sekunder merupakan teks historis, sosial, dan kultural yang mendukung, yang berhubungan dengan cerpen.

Metode dan teknik pengumpulan data ini pada dasarnya adalah seperangkat cara atau teknik yang merupakan perpanjangan dari indra manusia karena tujuannya adalah mengumpulkan fakta-fakta empirik yang terkait dengan masalah penelitian (Faruk, 2012: 25). Langkah pengumpulan data diawali dengan pembacaan berulang terhadap objek material, yakni cerpen "Perempuan Sinting di Dapur". Kemudian, pengelompokan data disesuaikan dengan landasan teori dan fokus penelitian. Selain dari novel, data dikumpulkan dari jurnal, buku-buku, dan kertas kerja lain yang berhubungan dengan pengarang dan cerpen.

Langkah selanjutnya adalah analisis data. Analisis data merupakan seperangkat cara atau teknik penelitian yang merupakan perpanjangan dari pikiran manusia karena fungsinya bukan untuk mengumpulkan data, melainkan untuk mencari hubungan antardata yang tidak akan pernah dinyatakan sendiri oleh data yang bersangkutan (Faruk, 2012: 25). Dalam tahap ini variabel-variabel yang ditemukan dalam proses pengumpulan data akan dicari hubungannya satu sama lain sehingga menjadi satu kesatuan. Berdasarkan latar belakang masalah yang telah diidentifikasi, analisis dilakukan untuk membongkar struktur transmisi memori dan wacana rekonsiliasi dalam cerpen. 


\section{PEMBAHASAN}

\section{Transmisi Memori dalam Cerpen "Perempuan Sinting di Dapur"}

Hirsch membagi transmisi memori menjadi dua macam, yakni transmisi familial (familial transmision) dan transmisi afiliatif (affiliatve transmission). Dalam subbab ini yang pertama akan dibahas adalah transmisi familial, yakni transmisi yang dilakukan dalam lingkup keluarga. Transmisi memori yang dilakukan antargenerasi dalam cerpen ini terbagi menjadi dua, yakni berbentuk narasi cerita dan perilaku. Seperti yang telah dijelaskan sebelumnya, dalam cerpen ini generasi yang memiliki trauma adalah generasi Saodah dan Haji Mail. Saodah memiliki trauma karena kehilangan suaminya yang menjadi korban dalam peristiwa 1965. Suaminya dituduh sebagai orang yang kafir dan syirik.

Transmisi memori dalam lingkup keluarga dalam cerpen ini dilakukan oleh Wak Haji Mail terhadap tokoh $a k u$ sebagai tokoh utama. Adapun transmisi memori yang terjadi dimediasi bukan dengan menggunakan narasi atau cerita, melainkan melalui perilaku Wak Haji Mail. Selama hidupnya, Wak Haji Mail selalu membantu hidup Saodah, seperti yang tampak dalam kutipan di bawah ini.

\footnotetext{
Di jalan, kukarang-karang sendiri ihwal sepotong cinta tak sampai Wak Haji Mail pada Mak Saodah. Persis seperti cintaku pada Aminah.

Beberapa menit usai kuajukan permintaan keluarga kami, Mak Saodah tetap bergeming. Sebelumnya, kubayangkan ia akan bergegas, merapikan dirinya dan sebentar kemudian duduk di boncengan motorku. Sekalipun Wak Haji Mail mengamalkan ilmu golok dalam perkara sedekah, semua orang kampung tahu kalau Mak Saodah seperti selalu menyimpan obat kikir di sayur dan lauk masakannya. Tak cukup mendirikan kakus dengan tangki septik, Wak Haji Mail mengirim orang untuk membangun lapak setengah permanen, menyemen lantai bagian depan rumah Mak Saodah, memasangkan listrik, dan menyekolahkan kelima anak Mak Saodah sampai SMA. Terakhir ia menghibahkan kulkas bekas istri keduanya supaya Mak Saodah bisa bikin sendiri es batu dan es lilin. Di depanku Mak Saodah masih tak bergerak. Matanya mulai berkaca-kaca dan sempat kukira ia terharu. Aminah, putri sulungnya, mendekat. Sejak tadi ia membisu di pojokan, mendengarkan. Kini ia meraba-raba punggung maknya, menenangkan. Kulihat sesaat, sepertinya rahang Mak Saodah bergemeretak. Aku tak yakin (Prasad, 2009).
}

Dalam kutipan di atas, tokoh $a k u$ melihat perbuatan baik yang dilakukan Wak Haji Mail terhadap Saodah. Selama hidupnya, Wak Haji Mail membantu kehidupan Saodah. Ia mendirikan kakus, membangun lapak Saodah, menyemen lantai depan rumah Saodah, memasang listrik, membantu menyekolahkan kelima anak Saodah, dan memberikan kulkas bekas agar bisa digunakan Saodah untuk berjualan es lilin. Perilaku yang dilakukan oleh Wak Haji Mail ini pun sempat membuat tokoh aku heran. Ketika menyaksikan Saodah menangis menjelang kematian Wak Haji Mail, tokoh aku berpikir bahwa ia menangis karena merasa berutang budi kepada Wak Haji Mail. 
Tidak hanya itu, perilaku Wak Haji Mail yang ditransmisikan dalam tokoh aku tampak ketika Wak Haji Mail meregang nyawa, seperti yang terlihat dalam kutipan di bawah ini.

\footnotetext{
Dinanti-nanti matinya, Wak Haji Mail malah mulai mengigau. Semula tak seorang pun menangkap apa yang dikatakannya. Kupikir bukan tak bisa. Tak mau, lebih tepatnya. Aku sendiri, begitu diizinkan mendengar langsung segera mencerna, bukan kata, melainkan sepotong nama. Gumam ini berulang di antara tarikan nafasnya yang payah. Saodah.

Dua minggu setelah rumah sakit menyerah dan mengembalikannya ke rumah, Wak Haji Mail belum juga dijemput Izrail. Keempat belas anak dari tiga pernikahannya semakin sulit meredam cemas, silih berganti berjaga di luar kamar, siap untuk memberontak dari pembagian harta waris yang tak adil. Tak mungkin adil.

Lepas maghrib tadi Haji Mail membuka mata dan mulutnya kembali bersuara. Satu jam kemudian semua orang terus berebutan masuk sehingga Wak Misnah naik pitam. Empat belas anak, beserta cucu-cucu, tentulah membuat keadaan bisa cepat berubah menjadi pasar malam. Itulah saatnya Wak Misnah, istri pertama Haji Mail, mengusir semua orang dan memanggilku masuk.

"Kau dengar?" tanya bibiku setengah membentak. Aku diam sebentar. Di depanku, Wak Haji terbaring seperti sepotong kayu. Lamat-lamat, di antara nafasnya yang berat, bisa kudengar suaranya, rendah dan kesakitan. Ke arah Wak Misnah, aku mengangguk.

"Panggilkan dia." Suara bibiku agak goyah, mengejutkanku. Apa yang dicemaskannya?

(Prasad, 2009).
}

Dalam kutipan di atas tampak Wak Haji Mail mengigau menyebut nama Saodah terus-menerus menjelang kematiannya. Tokoh aku pun bergegas menemui Saodah untuk memintanya datang menemui Wak Haji Mail. Namun, sayangnya hasilnya nihil. Alih-alih bersedia, Saodah malah menolaknya. Ia masuk ke rumahnya dan meraung-raung. Hal itu pun membuat tokoh aku penasaran. Rasa penasaran tersebut timbul karena transmisi memori kepada tokoh aku bersifat spasial. Ia pun mengalami krisis dan mencari tahu mengenai memori yang didapatkannya tersebut untuk ia rekonstruksi.

Tokoh $a k u$ pun mendapat transmisi memori afilial. Transmisi memori jenis ini pada dasarnya merupakan transmisi yang dilakukan di luar keluarga. Jadi, pada jenis ini proses transmisi berasal dari seseorang yang ada di luar keluarga. Tokoh aku mendapatkan transmisi memori yang dimediasi oleh perilaku Saodah ketika ia menginjak usia delapan tahun, seperti yang tampak dalam kutipan di bawah ini.

Aku duduk diam dan berusaha memecahkan kebingunganku. Lama. Sepuluh menit kemudian, Aminah sepertinya mulai kasihan pada wajahku yang merot-perot karena tak paham. la memanggilku mendekat. Aku datang dengan sigap, tapi ia cepat menempelkan jari telunjuk di mulutnya, matanya membeliak nakal mengancam. Aku memperhalus langkahku, mendekatinya tanpa suara. la membungkuk di dekat tirai dapur, aku mengikutinya. Sesaat kuingat, kami berdua sebagai bocah berumur delapan tahun, 20 tahun yang lalu, berjingkat mengintip Mak Saodah. Dulu, jauh sebelum mencapai tirai dapur Mak Saodah sudah membentak kami. Kini suara bentakan itu tak kunjung datang. Aku menunduk di belakang Aminah. Kami sangat dekat, aku bisa melihat tengkuk di bawah gelung rambutnya, mencium wangi tubuhnya, rambutnya. Lehernya, siap menenggelamkanku. Aku agak mabuk, tak percaya. Sesaat bahkan kegirangan meluap-luap dan jantungku berdebar. Jari-jari Aminah yang cantik menyibak tirai dapur (Prasad, 2009). 
Dalam memori yang dimiliki tokoh $a k u$ ternyata terdapat ingatan saat ia pernah dibentak oleh Saodah ketika ia dan Aminah berusia delapan tahun. Ketika tokoh aku dan Aminah hendak pergi ke dapur Saodah, ia dibentak. Hal itu pun membuat tokoh $a k u$ penasaran mengapa ia dan Aminah diperlakukan seperti itu, padahal keduanya hanya ingin pergi ke dapur. Ketika dewasa, tokoh $a k u$ pun mendapatkan transmisi memori yang hampir serupa. Ia melihat apa yang dilakukan oleh Saodah ketika ia memasak, seperti yang tampak dalam kutipan di bawah ini.

Aku tak ingat apakah Aminah sempat menjawab, sebab dari dalam dapur maknya membuatku terperangah.

Mak Saodah sedang mengangkat kainnya tinggi-tinggi, melewati lutut, lalu berdiri setengah jongkok mengangkangi salah satu panci yang isinya mulai mendidih. Raut wajahnya, gabungan yang ganjil antara mengejan dan kebencian, mengerikan. Sedetik kemudian, dari tempatnya berdiri, kudengar suara desing yang akrab dan gemericik air jatuh ke panci. Mak Saodah meludah lagi ke panci, sekali. Desing dan gemericik itu belum selesai ketika mata Mak Saodah menusuk tajam, menatapku (Prasad, 2009).

Selain itu, tokoh aku juga mendapat transmisi memori afilial berupa narasi cerita. Ia mendapatkan transmisi memori afilial dari Aminah, seperti yang terlihat pada kutipan berikut.

Aku tercekat sebentar sebelum menggeleng. Di antara perasaan cekat dan gelengan kepalaku sempat terpikir untuk mengutarakan rahasia yang diceritakan Aminah padaku. Rahasia yang sesungguhnya tak terang karena hanya berupa garis-garis besar. Haji Mail berdosa pada Mak Saodah. Suaminya, ayah Aminah, difitnah murtad, syirik, musyrik, kafir, diasingkan orang sekampung seperti penderita kusta, dibiarkan mati tanpa harga diri.

Kuurungkan pikiran ini ketika kudengar Haji Mail mengerang. Erangnya panjang, kesakitan dan menyakitkan. Aku yakin pilihanku tepat. Tak perlu kuceritakan, Haji Mail ingat (Prasad, 2009).

Dalam kutipan di atas tampak bahwa tokoh aku mengalami transmisi memori yang berlangsung afilial dalam ranah intragenerasi. Ia diberi tahu alasan Saodah tidak mau menemui Wak Haji Mail. Ternyata, Wak Haji Mail adalah salah satu orang yang terlibat dalam kematian suami Saodah. Wak Haji Mail adalah orang yang mendiskriminasi suami Saodah hingga ia meninggal karena difitnah murtad, syirik, musyrik, kafir, lalu diasingkan orang sekampung. Setelah seorang post-generation mendapat transmisi memori, generasi selanjutnya atau post-generation pun mengalami krisis.

Memori yang ditransmisikan kepada post-generation bukan memori yang utuh, tetapi bersifat parsial. Dari berbagai memori yang ditransmisikan kepadanya yang berbentuk potongan-potongan tersebut, tokoh aku pun melakukan rekonstruksi memori. Ia mulai menghubung-hubungkan satu memori dengan memori lainnya dan mulai memahami apa yang terjadi. Ia paham bahwa apa yang dilakukan oleh Wak Haji Mail kepada Saodah bukan sesuatu yang tidak bermakna. Namun, ia melakukannya karena ia merasa bersalah 
kepada Saodah. Ia mengalami trauma sebagai seorang pelaku atau perparator. Gagasan di balik trauma pelaku adalah bahwa "pelaku dapat mengalami kejahatan mereka sebagai trauma" (Mohamed, 2015; Morag, 2013). Tindakan direktif dan performatif dari kekejaman/kejahatan itu sendiri "menyebabkan cedera psikologis pada pelaku, yang dapat mengakibatkan konsekuensi fisik, sosial, atau emosional yang merugikan” (Mohamed, 2015). Karena itu, pelaku mengalami gejala traumatis yang mirip dengan korban. Gejalagejala ini dapat mencakup beberapa atau semua dari hal berikut: kilas balik yang mengganggu dan berulang; penghindaran tempat/orang/kegiatan trauma asli; insomnia; mimpi buruk; takut; paranoia; dan disasosiasi (American Psychiatric Association, 2006).

\section{Ugoran Prasad dan Upaya Rekonsiliasi}

Ugoran Prasad merupakan salah seorang penulis Indonesia yang juga merangkap sebagai seorang musisi. Cerpen-cerpennya telah tersebar di berbagai media massa dan terhimpun dalam berbagai buku, di antaranya Di Etalase (2004), Waktu Batu (2004), Ripin (2007), Cinta di Atas Perahu Cadik (2008), Smokol (2009), dan Kumpulan Budak Setan (2010). Selain itu, bersama grup band-nya, Melancholic Bitch, ia telah mengeluarkan beberapa album, yakni "Balada Joni dan Susi", "NKKBS Bagian Pertama", dan "ReAnamnesis". Cerpen "Perempuan Sinting di Dapur" merupakan salah satu cerpen yang ditulis oleh Ugoran Prasad dan diterbitkan oleh Kompas pada tahun 2008. Kemudian, cerpen tersebut dibukukan dalam Smokol: Cerpen KOMPAS Pilihan 2008 (2009). Secara garis besar, dalam cerpen tersebut diangkat Peristiwa 1965 yang terjadi di Indonesia dan trauma yang diakibatkan olehnya, baik dari sisi korban maupun pelaku. Hal itu tampak dalam kutipan berikut.

\footnotetext{
Aku tercekat sebentar sebelum menggeleng. Di antara perasaan cekat dan gelengan kepalaku sempat terpikir untuk mengutarakan rahasia yang diceritakan Aminah padaku. Rahasia yang sesungguhnya tak terang karena hanya berupa garis-garis besar. Haji Mail berdosa pada Mak Saodah. Suaminya, ayah Aminah, difitnah murtad, syirik, musyrik, kafir, diasingkan orang sekampung seperti penderita kusta, dibiarkan mati tanpa harga diri (Prasad, 2009).
}

Dalam konteks kutipan di atas, suami Saodah merupakan korban pembantaian terhadap orang-orang yang dianggap komunis atau berafiliasi dengan komunis. Hal itu dapat dilihat dari adanya pembunuhan massal yang disebabkan oleh pelabelan kafir dan murtad yang dilakukan oleh masyarakat. Hal itu juga dapat dilihat dalam catatan Tim Tempo (2012) yang membahas pengakuan para algojo 1965. Salah satu liputannya membahas mengenai pembantaian massal terhadal orang-orang yang dianggap komunis 
atau berafiliasi terhadap mereka di Kediri, Jawa Timur. Pembantaian itu dilakukan karena anggapan bahwa orang-orang komunis harus dibunuh karena apabila tidak dibunuh, mereka akan membunuh dan membantai kaum muslim (Tim Tempo, 2012: 56-58).

Ugoran Prasad dalam penulisan novel ini mendapatkan memori afiliatif. Ugoran Prasad lahir dan besar di Tanjung Karang, Bandarlampung. Ia tinggal di keluarga kelas menengah yang menikmati privilese tertentu. Meskipun demikian, ternyata ia tidak sepenuhnya nyaman dengan privilese tersebut. Bapaknya berprofesi sebagai pegawai negeri, sedangkan ibunya berprofesi sebagai guru Agama. Mereka tinggal di perkampungan kecil yang ia sebut sebagai "hidup hand-to-mouth" atau hidup serbaberkecukupan (Ibrahim, 2017). Beberapa peristiwa yang terjadi di lingkungannya membuat ia mulai sadar akan narasi yang dibuat oleh Orde Baru waktu itu, terutama narasi mengenai Peristiwa 1965.

Narasi tersebut mulai mengusiknya ketika ia dan teman-temannya mengikuti les privat oleh salah seorang guru Fisika. Saat itu ia dan teman-temannya mengagumi kepintaran sang guru. Namun, ia heran, mengapa guru tersebut tidak diizinkan untuk mengajar di sekolah formal. Usut punya usut, ternyata guru tersebut tidak diperbolehkan mengajar di sekolah formal karena ia merupakan seorang lulusan universitas di Rusia.

\footnotetext{
"Lalu, kami mendapat informasi bahwa Bapak ini enggak boleh mengajar di sekolah formal lagi karena dia dulu lulusan Rusia. Kami mulai penasaran, 'Memangnya kenapa kalau dia lulusan Rusia?’” Seiring ia tumbuh dewasa, Ugoran tambah peka terhadap "kejanggalan-kejanggalan kecil" semacam ini. "Bapakku dulu punya buku Bumi Manusia dan Jejak Langkah-nya Pramoedya Ananta Toer, dan kedua buku itu enggak pernah ditaruh di rak," kisah Ugo. "Cuma ditaruh di kamarnya, dan dalam situasi apapun, buku itu enggak boleh keluar ke ruang tengah. Jadi, ada banyak keanehan yang begitu. Di balik sesuatu yang rapi - atau dirapikan - seperti ada sesuatu yang tidak beres." (Ibrahim, 2017).
}

Dari kutipan di atas dapat dilihat bahwa pertanyaan ini pun akhirnya membuat Ugoran Prasad mulai memperhatikan kejanggalan-kejanggalan yang terjadi di sekitarnya, seperti ayahnya yang menyimpan buku-buku Pramoedya Ananta Toer di dalam kamar, bukan ditaruh di rak buku.

Lebih lanjut, Peristiwa 1965 memang menjadi memori traumatik tersendiri bagi Ugoran Prasad. Memori itu diperolehnya dari menonton film "Pemberontakan G30S/PKI" yang selalu diputar oleh pemerintah setiap tahun, seperti yang terlihat dalam kutipan berikut.

"Susah banget aku lepas dari adegan pertama: orang-orang bawa celurit, menyerbu masjid dan gereja," kenang Ugo. "Atau, darah orang tua yang mengguyur ke anaknya. Menurutku, itu ada di tubuh banget. Kamu merasakan ngeri itu sampai ke tubuhmu. Karena film itu afektif, dia politik emosi, dia sama sekali enggak rasional." (Ibrahim, 2017). 
Dalam kutipan di atas tampak bagaimana narasi mengenai Peristiwa 1965 yang dibuat oleh Pemerintah Orde Baru ditransmisikan kepada Prasad melalui film "Pemberontakan G30S/PKI”. Film yang diputar berulang-ulang setiap tahun ini menjadi trauma tersendiri bagi Prasad. Di dalam konteks ini Prasad mengalami transmisi memori melalui afilial, yakni hal-hal di luar keluarga. Memori tersebut diperoleh dari institusi, yakni negara yang sengaja memutarnya sebagai alat propaganda. Hal itu menyebabkan citra mengenai Peristiwa 1965 dan PKI pun sesuai dengan narasi yang dibuat oleh pemerintah.

"Aku enggak paham seluruh adegan rapat Politbiro," lanjut Ugo. "Sebagai anak kecil, kita enggak tahu sebab-akibat. Yang aku tahu cuma, PKI ini ngeri. Tampang mereka seram, mereka merokok Dji Sam Soe, dan musiknya seram. Pokoknya yang kami tahu, mereka itu orang-orang jahat. Mereka jahat ke kita, kita melawan, dan kita menang. Orang Indonesia sekarang adalah pemenang karena mereka sudah tidak ada lagi. Narasinya begitu."

"Orang meninggal, lho, pas nonton film itu," tuturnya. "Mereka sampai injak-injakkan di Jawa Timur gara-gara film itu. Anak-anak kecil yang nonton film itu pada menjerit di dalam ruangan!" Nada suaranya berubah menjadi separuh jijik, separuh terperangah. "Anak SD umur 8 tahun kamu suruh melihat adegan orang menyilet orang lain. Gila apa? Lapisan traumanya lebar banget."

(Ibrahim, 2017)

Lebih lanjut, menurutnya film propaganda tersebut tidak hanya menimbulkan trauma terhadap dirinya secara pribadi, tetapi juga terhadap anak-anak dari generasinya. Hal itu disebabkan oleh adegan-adegan sadis yang secara eksplisit dihadirkan di dalam film tersebut. Karena trauma yang dialami oleh generasinya tersebut, ia berpendapat bahwa wacana mengenai Peristiwa 1965 pun ia anggap memuakkan sehingga ia tolak terus-menerus.

Namun, bagi Ugoran, warisan paling mendalam dari propaganda film "Pemberontakan G30S/PKI" terasa dalam bentuk wacana politik dan watak masyarakat kita saat ini.

"Film ini ditonton satu generasi, angkatan yang sekarang umur 40-an tahun," ucap Ugo. "Bagi generasi ini, sejarah politik Indonesia menjadi politik emosi. Sejak awal, emosi sudah meminggirkan segalanya. Dari yang kamu lihat dan kamu dengar soal PKI saja kamu sudah muak, dan barangkali kamu trauma."

\footnotetext{
“Makanya susah banget untuk membahas komunisme dan sejarah 1965 sampai sekarang," keluhnya. "Kita cuma bisa melihat mereka sebagai hantu masa kecil. Kita sudah tidak bisa memandangnya secara obyektif. Kita bisa bilang bahwa ada pemikir yang membahas Marxisme dari sudut pandang Islam, tapi enggak bakal tembus. Pokoknya kalau lo komunis, lo pasti atheis. Urutan yang otomatis ada di pikiran kita begitu. Upaya meluruskan sejarah jadi susah banget." (Ibrahim, 2017)
}

Dalam kutipan di atas tampak bahwa Ugoran Prasad menekankan dampak traumatik yang diakibatkan oleh transmisi memori melalui film propaganda "Pemberontakan 
G30S/PKI" menyebabkan generasinya menolak utuk membahas komunisme dan sejarah 1965. Peristiwa itu dianggapnya tidak lebih dari sebuah hantu masa kecil yang tidak bisa dipandang lagi secara objektif. Akibatnya, pelurusan sejarah itu pun cukup sulit.

Berdasarkan pernyataan yang dikeluarkan oleh Ugoran Prasad tersebut, dapat dilihat bahwa ia berusaha untuk memunculkan kembali wacana mengenai Peristiwa 1965. Namun, dalam cerpen "Perempuan Sinting di Dapur" ia tidak menandingi wacana mengenai Peristiwa 1965, tetapi ia menghadirkan dampak yang ditimbulkan karena adanya peristiwa tersebut. Ia memperlihatkan bahwa Peristiwa 1965 menjadi persoalan yang cukup traumatis, baik bagi korban maupun bagi pelaku. Bagi korban, Peristiwa 1965 menyebabkan luka yang begitu dalam hingga dapat menyebabkannya melakukan hal-hal di luar batas kewajaran, seperti balas dendam dengan menjual makanan yang telah diludahi dan dikencingi kepada warga kampungnya. Di sisi lain, peristiwa itu juga menyebabkan trauma bagi para pelakunya yang direpresentasikan oleh Wak Haji Mail. Sebagai pelaku, ia merasa bersalah karena telah memfitnah suami Saodah sehingga menyebabkan kehidupan Saodah menjadi sengsara.

Di dalam konteks tersebut dapat dilihat adanya upaya rekonsiliasi yang dilakukan oleh Ugoran Prasad. Ia ingin melakukan rekonsiliasi para korban, pelaku, dan juga postgeneration yang mengalami trauma mendalam akibat Peristiwa 1965 melalui karya sastra. Rekonsiliasi perlu dilakukan karena adanya kebutuhan untuk menebus masa lalu yang menyakitkan demi masa depan yang sama (Schaap, 2005: 17). Ia ingin melakukan trauma healing terhadap para post-generation yang sudah muak dan enggan membicarakan hal-hal mengenai Peristiwa 1965 karena adanya trauma yang ditransmisikan melalui film "Pemberontakan G30S/PKI".

\section{SIMPULAN}

Dari pemaparan sebelumnya dapat dilihat adanya dua macam transmisi memori yang tidak menyenangkan atau trauma yang terdapat dalam cerpen "Perempuan Sinting di Dapur" karya Ugoran Prasad, yakni transmisi familial dan transmisi afilial. Kedua transmisi tersebut dapat dibagi menjadi dua, yakni transmisi memori yang dimediasi oleh cerita atau narasi dan transmisi memori yang dimediasi oleh perilaku. Namun, dari kedua jenis ini, transmisi memori yang dimediasi oleh perilaku cukup dominan di dalamnya. Baik korban maupun pelaku memiliki trauma terpendam yang gagal untuk direkonsiliasi. Alih- 
alih membicarakannya, keduanya menyimpan dendam dan rasa bersalah. Akibatnya, trauma tersebut ditransmisikan melalui perilaku.

Bentuk memori tersebut adalah matinya suami Saodah atau ayah Aminah yang disebabkan oleh fitnah Wak Haji Mail. Ia dituduh orang murtad dan kafir yang dalam konteks ini mengacu pada Peristiwa 1965. Pada saat itu orang yang dilabeli sebagai komunis atau orang yang berafiliasi dengan komunis akan dibunuh. Transmisi tersebut dilakukan sebagai bentuk upaya balas dendam atas luka yang dialami oleh Saodah kepada warga di kampungnya yang telah memfitnah suaminya sehingga keluarganya diasingkan dan dikucilkan. Kemudian, transmisi afilial intragenerasi dilakukan oleh tokoh Aminah terhadap tokoh $a k u$.

Pemunculan Peristiwa 1965 dalam cerpen ini merupakan bentuk dari rekonsiliasi yang ingin dilakukan oleh Ugoran Prasad. Ia merupakan bagian dari post-generation yang mengalami trauma mendalam mengenai Peristiwa 1965. Transmisi yang dilakukan oleh Pemerintah Orde Baru mengenai Peristiwa 1965 melalui film propaganda "Pemberontakan G30S/PKI" yang diputar terus-menerus membuat generasi Ugoran Prasad menjadi muak dan enggan membicarakan peristiwa tersebut.

\section{DAFTAR PUSTAKA}

American Psychiatric Association. (2006). Practice Guidelines for the Treatment of Psychiatric Disorders. Arlington: American Psychiatric Association. https://doi.org/10.1176/appi.books.9780890423363

Anderson, B. (2006). Becoming and being hopeful: Towards a theory of affect. Environment and Planning D: Society and Space, 24, 733-752. https://doi.org/10.1068/d393t

Assa, A. E. P. (2019). Postmemory dalam Novel Tapol Karya Ngarto Februana. Jurnal Poetika: Jurnal Ilmu Sastra, 7(1), 17-31.

Faruk. (2012). Metode Penelitian Sastra: Sebuah Penjelajahan Awal. Yogyakarta: Pustaka Pelajar.

Hirsch, M. (1992). Family Pictures: Maus, Mourning, and Post-Memory. Discourse, 15(2, Special Issue: The Emotions, Gender, and the Politics of Subjectivity (Winter 1992-93)), 3-29.

Hirsch, M. (2012). The Generation of Postmemory: Writing and Visual Culture After Holocaust. New York: Colombia University Press.

Ibrahim, R. (2017). Trauma Irama Ugoran Prasad. Diambil 27 Desember 2018, dari Jurnal Ruang website: https://jurnalruang.com/read/1508942178-trauma-irama-ugoran-prasad

Jati, G. P. (2020). Transmisi Memory Queer dan Wacana Counter Memory dalam Novel Tiba Sebelum Berangkat Karya Faisal Oddang: Kajian Postmemory. Universitas Gadjah Mada.

Jones, P. I., \& Osborne, T. (2020). Analysing virtual landscapes using postmemory. Social \& Cultural Geography, 21(2), 186-206. https://doi.org/10.1080/14649365.2018.1474378

Mohamed, S. (2015). Of Monsters and Men: Perpetrator Trauma and Mass Atrocity. Columbia Law Review, 115, 157-216.

Morag, R. (2013). Perpetrator Trauma and Current Israeli Documentary Cinema. Camera Obscura, 27(2/80), 93-133. https://doi.org/10.1215/02705346-1597222 
Transmisi Memori dan Wacana Rekonsiliasi...

Prasad, U. (2009). Perempuan Sinting di Dapur. In Smokol: Cerpen KOMPAS Pilihan 2008. Jakarta: Penerbit Buku Kompas.

Putra, J. N. I. (2018). Konstruksi Bima Dan Ekalaya Dalam Novel Pulang Karya Leila S. Chudori Kajian Postmemory. Universitas Gadjah Mada.

Saputro, G. (2013). Jakarta 2039: Membangun Monumen Ingatan Tragedi Kekerasan. Jurnal Jentera, 2(1), 21-33. https://doi.org/10.26499/jentera.v2i1.389

Schaap, A. (2005). Political Reconciliation. London and New York: Routledge. https://doi.org/10.4324/9780203002773

Tim Tempo. (2012). Tentara, Santri, dan Tragedi Kediri. Liputan Khusus Tempo: Pengakuan Algojo 1965. 